\title{
Prematurity is a significant predictor of worse outcomes in viral bronchiolitis: A comparative study in infancy
}

\author{
Original \\ Article \\ Noussa R. El Basha', Huda Marzouk', May M. Sherif ${ }^{2}$,Amani A. El Kholy ${ }^{2}$ \\ ${ }^{I}$ Departments of Pediatrics, ${ }^{2}$ Clinical Pathology, Faculty of Medicine, Cairo University, \\ Cairo, Egypt
}

\begin{abstract}
Background: The rate of admissions to hospital with bronchiolitis has increased over the past years. The reasons for this are likely to be multifactorial including improved survival of preterm infants.

Aim: To assess the severity of viral bronchiolitis in preterm compared with term infants admitted at a tertiary hospital in Cairo, Egypt, based on the outcome.

Materials and Methods: This prospective study was conducted throughout a 3-year period from September 2011 to October 2014. It included 153 infants, 74 healthy preterm and 79 healthy term infants, admitted with clinical diagnosis of bronchiolitis at a tertiary hospital in Cairo, Egypt. Bronchiolitis severity score (BSS) was recorded, and nasopharyngeal swabs were obtained from each patient at the time of presentation. Viruses were identified using reverse transcription PCR. The clinical course and patient's outcome were recorded.

Results: This study recorded a significantly more severe BSS for preterm compared with term infants. The preterm group had an increased mean length of hospital stay and oxygen therapy and were more likely to need ICU admission and mechanical ventilation compared with the term group. The mean \pm SD BSS for infections with human metapneumovirus, respiratory syncytial virus, parainfluenza 3 was more significantly severe in preterm compared with term infants. Bacterial co-infection was significantly correlated with severity scoring in both groups..

Conclusion: Prematurity significantly affects the severity of bronchiolitis, and this underscores the importance of early categorization of these infants as a high-risk group on their first visit. Physician should be aware that their illness runs a more severe course, even if they have no underlying disorders.
\end{abstract}

Received: 17 Aug 2017, Accepted: 23 Dec 2017

Key Words: Bronchiolitis, preterm, severity, viruses.

Corresponding Author: Noussa R. El Basha, M.D., Department of Pediatrics, Faculty of Medicine, Cairo University, Cairo, Egypt, Tel.: +20 120555 1920, E-mail: noussaelbasha3@yahoo.com

ISSN: 0013-2446, Vol. 92, No.3

\section{INTRODUCTION}

Bronchiolitis is the most common lower respiratory tract infection in children less than 1 year of age and is usually of viral etiology ${ }^{[1]}$. Human respiratory syncytial virus (RSV) is the most commonly affecting virus and identified in $60-70 \%$ of hospitalized infant with bronchiolitis ${ }^{[2]}$. Bronchiolitis by itself accounts for the greatest number of hospitalization in infancy during the fall and winter season $^{[3]}$.

Bronchiolitis is a self-limiting condition but may be life-threatening causing significant severe illness ${ }^{[4-6]}$; it is the most common cause of hospital admission for infants beyond the neonatal period, with rate varying between 1 and $3 \%$. Furthermore, $\sim 10 \%$ of hospitalized infants will need intensive care admission ${ }^{[7-10]}$.

The rate of admissions to hospital with bronchiolitis has increased over the past 10 years. The reasons for this are not fully understood and are likely to be multifactorial and include improved survival of preterm infants ${ }^{[11]}$. Epidemiological evidence revealed that young age $(<6-12$ weeks) and premature birth ( $<37$ weeks) are associated with high risk of severe bronchiolitis ${ }^{[7,12,13]}$.

The aim of the present study was to assess the severity of viral bronchiolitis in healthy preterm compared with healthy term infants in terms of the duration of hospital stay, oxygen saturation, duration of oxygen requirement, and ICU and/or mechanical ventilation (MV) requirement.

\section{MATERIALS AND METHODS}

\section{Study design and patients}

This prospective study was conducted throughout a 3-year period from September 2011 to October 2014. It included 153 infants in the first year of life with clinical diagnosis of bronchiolitis, according to American Academy of Pediatrics ${ }^{[14]}$. All were admitted to inpatient departments at Cairo University Specialized Pediatric Hospital. 
Seventy-four of those infants were healthy preterm ( $<37$ weeks) and 79 infants were healthy term. The following specific groups were excluded: neonates, recurrent wheeze, and association of underlying chronic diseases.

\section{Methods}

All patients were subjected to thorough history taking, including demographic data, and also, full physical examination was performed with emphasis on signs of respiratory tract infection. The respiratory severity score that has been used in this study is the modified Tal score. This score ranges from 0 to 12 , with a higher score indicating more severe disease. Each score is an aggregate of assigned values ranging from 0 to 3 in categories of respiratory rate, retractions, wheezing, and oxygen saturation in room air ${ }^{[15]}$. Bronchiolitis severity score (BSS) was recorded for each patient at the time of presentation. Subsequently, during inpatient management, the following data were recorded: the clinical course was observed during the hospital stay, including the need for ICU admission, need for MV, duration of oxygen therapy, and duration of hospital stay.

\section{Clinical specimens}

Complete blood count and C-reactive protein were determined at the time of study enrollment for each patient. Oropharyngeal and nasopharyngeal swabs were obtained for PCR at the time of presentation and put in viral transport media.

\section{Molecular identification of respiratory viruses}

Total nucleic acid was extracted from the nasopharyngeal/oropharyngeal swabs by the automated KingFisher Flex Magnetic Particle Processor (Thermo Scientific, Waltham, Massachusetts, USA) using MagMAX Total Nucleic Acid Isolation Kit (Cat No. AM 1840; Applied Biosystems, Foster City, California, USA) according to the manufacturer's instructions. All the viral targets were amplified using specific primers and probes produced by the Center of Disease Control and Prevention (CDC), Atlanta, Georgia, USA, and following the standard protocol for quantitative reverse transcription PCR detection.

Detection of influenza viruses was conducted in the Cairo University Hospital Laboratory and confirmed by the Naval Medical Research Unit No.3 (NAMRU-3) Laboratory. The samples were screened for the presence of influenza A and B using the CDC kit for influenza following CDC protocol ${ }^{[16]}$. Samples positive for influenza A were further subtyped according to the CDC protocol to the following types: pandemic influenza 2009 A(H1N1), seasonal $\mathrm{H} 1$, and $\mathrm{H} 3$.

Testing for adenovirus, human parainfluenza viruses 1 , 2, and 3, RSV, and human metapneumovirus (hMPV) was done at NAMRU-3 laboratory by reverse transcriptionqPCR using CDC-specific primers and probes and following a CDC protocol for the detection of noninfluenza viruses. Samples were considered positive to the viral target if the amplification curve crossed the threshold line before cycle 40. All clinical samples had to be positive for the human RNAse P gene (RP), with a Ct value less than or equal to 37, for validation. A positive control for each virus was added to each run to ensure adequate amplification of the target genes.

\section{Statistical analysis}

Precoded data were entered on the statistical package of social science software program, version 23 (IBM SPSS Statistics for Windows, version 23.0; IBM Corp., Armonk, New York, USA) to be statistically analyzed. Data were presented using mean and SD for quantitative variables and frequency and percentage for qualitative ones. Comparison between groups was performed using independent sample t-test or Mann-Whitney for quantitative variables and $\chi^{2}$ test and Fisher's exact test for qualitative ones. Spearman's correlation coefficient was used to estimate the association between different quantitative variables. $\mathrm{P}$ values less than 0.05 were considered statistically significant.

\section{Ethical considerations}

This study was approved by Cairo University Clinical Research Ethics Committee, and informed verbal consents were obtained from parents of the included children. The study design conformed to the Revised Helsinki Declaration of Bioethics.

\section{RESULTS}

The study included 153 infants with a clinical diagnosis of acute bronchiolitis in otherwise healthy infants. Seventynine of them were term and 74 were preterm infants. The detailed demographic characteristics including risk factors for bronchiolitis of both preterm and term infants are summarized in Table 1 . Preterm infants were significantly younger than term infants $(P=0.001)$. 
Table 1: Demographic characteristics of preterm and term infants with bronchiolitis, Cairo University Specialized Pediatric Hospital

\begin{tabular}{|c|c|c|c|}
\hline Variables & $\begin{array}{c}\text { Preterm infants }(n=74) \\
{[n(\%)]}\end{array}$ & $\begin{array}{l}\text { Term infants }(n=79) \\
{[n(\%)]}\end{array}$ & $P$ value \\
\hline Age (mean \pm SD) (months) & $5.2 \pm 4.1$ & $7 \pm 4.2$ & $0.001 *$ \\
\hline \multicolumn{4}{|l|}{ Sex } \\
\hline Male & $36(48.6)$ & 41 (51.9) & 0.747 \\
\hline Female & $38(51.4)$ & $38(48.1)$ & \\
\hline History of passive smoking & $46(62.2)$ & $41(51.9)$ & 0.253 \\
\hline Nonexclusive breast feeding & $32(43.2)$ & $27(34.2)$ & 0.319 \\
\hline
\end{tabular}

$* P<0.05$, statistically significant.

Clinical findings at the time of presentation, BSS, and outcomes of both groups are shown in Table 2. BSS (mean $\pm \mathrm{SD}$ ) was significantly more severe for preterm compared with term infants at the time of presentation $(P=0.045)$. Moreover, preterm group had an increased mean length of hospital stay and mean duration of oxygen therapy compared with term group $(P=0.002$ and 0.001 , respectively). Preterm infants were significantly more likely to need ICU admission $(P=0.007)$ and MV $(P=0.033)$ than term infants.

Table 2: Clinical findings on presentation and outcomes of the preterm and the term infants with bronchiolitis

\begin{tabular}{|c|c|c|c|}
\hline Variables & Preterm infants $[\mathrm{n}(\%)]$ & Term infants $[\mathrm{n}(\%)]$ & $P$ value \\
\hline Respiratory rate (mean $\pm \mathrm{SD}$ ) & $54.7 \pm 10.2$ & $47.8 \pm 10.5$ & $<0.001^{*}$ \\
\hline \multicolumn{4}{|l|}{ Respiratory distress $[\mathrm{n}(\%)]$} \\
\hline No RD & $10(13.51)$ & $28(35.4)$ & $0.003^{*}$ \\
\hline Grade 1 & $10(13.51)$ & $12(15.2)$ & 0.821 \\
\hline Grade 2 & $16(21.62)$ & $13(16.5)$ & 0.536 \\
\hline Grade 3 & $30(40.55)$ & $24(30.4)$ & 0.236 \\
\hline Grade 4 & $8(10.81)$ & $2(2.5)$ & 0.051 \\
\hline Lethargy & $28(37.8)$ & $9(11.4)$ & $<0.001^{*}$ \\
\hline No drink & $34(45.9)$ & $46(58.2)$ & 0.147 \\
\hline Seizures & $4(5.4)$ & $2(2.5)$ & 0.431 \\
\hline Vomiting & $16(21.6)$ & $36(45.6)$ & $0.002 *$ \\
\hline Oxygen saturation (mean $\pm \mathrm{SD}$ ) & $85.4 \pm 13.1$ & $90.6 \pm 9.7$ & 0.016 \\
\hline Duration of oxygen therapy (mean \pm SD) & $4.4 \pm 1.7$ & $2.9 \pm 1.4$ & $0.001 *$ \\
\hline PICU admission [n (\%)] & $18(24.3)$ & $6(7.6)$ & $0.007 *$ \\
\hline Duration of PICU admission (mean $\pm \mathrm{SD}$ ) & $3.8 \pm 1.3$ & $3.2 \pm 0.4$ & 0.186 \\
\hline Mechanical ventilation [n (\%)] & $12(16.2)$ & $4(5.1)$ & $0.003 *$ \\
\hline Duration of MV (mean $\pm \mathrm{SD}$ ) & $3.3 \pm 1.0$ & $2.5 \pm 1.0$ & 0.128 \\
\hline Duration of hospital stay (mean $\pm \mathrm{SD}$ ) & $5.4 \pm 1.6$ & $4.0 \pm 1.6$ & $0.002 *$ \\
\hline \multicolumn{4}{|l|}{ Bronchiolitis severity score } \\
\hline Mean \pm SD & $9.6 \pm 3.8$ & $8.3 \pm 3.3$ & $0.045^{*}$ \\
\hline Severe bronchiolitis [n (\%)] & $36(48.6)$ & $26(32.9)$ & 0.051 \\
\hline
\end{tabular}

MV: mechanical ventilation, RD: respiratory distress.

$* P<0.05$, statistically significant. 
Viral screening results are summarized in Table 3. Respiratory viruses were detected in $36(48.6 \%)$ preterm patients and in $53(67 \%)$ term patients with acute bronchiolitis. RSV was the most commonly detected virus in both groups, although more significantly frequent in term infants $(57 \%)$ than preterm infants $(32.4 \%)(P=0.003)$. On the contrary, adenovirus was more significantly frequent in preterm than term infants (16.2 and 5.1\%, respectively; $P=0.033)$. Concomitantly with the viral respiratory infection, preterm patients had more frequent concomitant bacterial infections than term, despite nonsignificance $(P=0.221)$.

On comparing BSS of different viral agents in preterm and term infants, the mean \pm SD score for hMPV, RSV, parainfluenza 3 was more significantly severe in preterm compared with term infants $(P=0.003,0.009$, and 0.013 , respectively), as shown in Table 4.

Table 3: Viral PCR results among preterm and term infants with bronchiolitis, Cairo University Specialized Pediatric Hospital

\begin{tabular}{|c|c|c|c|}
\hline Viruses & $\begin{array}{l}\text { Viral positive in preterm } \\
\text { infants }(\mathrm{n}=36) \\
{[\mathrm{n}(\%)]}\end{array}$ & $\begin{array}{l}\text { Viral positive in term } \\
\text { infants }(\mathrm{n}=53) \\
{[\mathrm{n}(\%)]}\end{array}$ & $P$ value \\
\hline RSV & $24(32.4)$ & $45(57)$ & $0.003 *$ \\
\hline Adenovirus & $12(16.2)$ & $4(5.1)$ & $0.033^{*}$ \\
\hline hMPV & $4(5.4)$ & $1(1.3)$ & 0.198 \\
\hline Influenza A & $8(10.8)$ & $2(2.5)$ & 0.051 \\
\hline Influenza B & $0(0.0)$ & $0(0.0)$ & - \\
\hline Parainfluenza 1 & $0(0.0)$ & $0(0.0)$ & - \\
\hline Parainfluenza 3 & $2(2.7)$ & $6(7.6)$ & 0.278 \\
\hline Mixed viral infection & $12(16.2)$ & $5(6.3)$ & 0.071 \\
\hline Co-infection with bacterial & $12(16.2)$ & $7(8.9)$ & 0.221 \\
\hline
\end{tabular}

hMPV: human metapneumovirus, RSV: respiratory syncytial virus.

$* P<0.05$, statistically significant.

Table 4: Correlation between screened viruses and bronchiolitis severity score in preterm and term infants

\begin{tabular}{lccc}
\hline & \multicolumn{2}{c}{ Outcomes } \\
\cline { 2 - 4 } Virus & Preterm & Bronchiolitis severity score (mean \pm SD) & $P$ value \\
\cline { 2 - 4 } RSV & $9.7 \pm 3.9$ & Term & $0.009^{*}$ \\
Adenovirus & $9.5 \pm 4.0$ & $7.4 \pm 3.1$ & 0.717 \\
hMPV & $11.0 \pm 1.2$ & $10.3 \pm 2.6$ & $0.003^{*}$ \\
Influenza A & $10.0 \pm 3.4$ & $5 \pm 0.0$ & 0.212 \\
Parainfluenza 3 & $13.0 \pm 0.0$ & $13.5 \pm 2.1$ & $0.013^{*}$ \\
\hline
\end{tabular}

hMPV: human metapneumovirus, RSV: respiratory syncytial virus.

$* P<0.05$, statistically significant.

On correlating BSS to screened viruses and outcome in both groups, mixed viral infection did not correlate with severity scoring of bronchiolitis in preterm and term groups $(P=0.723,0.537$, respectively). However, bacterial co-infection was significantly correlated with severity scoring in both groups $(P<0.001)$. Moreover, we found significant correlation between BSS and need for admission. In addition, there were significant correlations between severity and duration of hospital stay and oxygen therapy, as shown in Table 5. 
Table 5: Correlation of bronchiolitis severity score with screened viruses and outcome in preterm and term infants

\begin{tabular}{|c|c|c|c|c|}
\hline Variables & BBS in preterm & $P$ value & BSS in term & $P$ value \\
\hline \multicolumn{5}{|l|}{ Screened virus (mean \pm SD) } \\
\hline hMPV & $11 \pm 1.2$ & 0.721 & $5 \pm 3.3$ & 0.329 \\
\hline RSV & $9.7 \pm 3.9$ & 0.676 & $7.4 \pm 3.1$ & $0.015^{*}$ \\
\hline Adenovirus & $9.5 \pm 4$ & 0.953 & $10.3 \pm 2.6$ & 0.233 \\
\hline Parainfluenza 3 & $13 \pm 00$ & 0.214 & $6.7 \pm 2.4$ & 0.189 \\
\hline Influenza A & $10 \pm 3.4$ & 0.7 & $13.5 \pm 2.1$ & $0.042 *$ \\
\hline Mixed viral infection & $9.8 \pm 3.6$ & 0.723 & $9.2 \pm 3.8$ & 0.537 \\
\hline Co-infection with bacterial & $13.7 \pm 1.0$ & $<0.001 *$ & $13.7 \pm 2.0$ & $<0.001^{*}$ \\
\hline \multicolumn{5}{|l|}{ Outcome $(r)^{\mathrm{a}}$} \\
\hline Duration of oxygen therapy & 0.653 & $<0.001 *$ & 0.721 & $<0.001^{*}$ \\
\hline Duration of hospital stay & 0.644 & $<0.001 *$ & 0.803 & $<0.001^{*}$ \\
\hline Duration of PICU admission & 0.304 & 0.220 & 0.310 & 0.550 \\
\hline
\end{tabular}

BSS: bronchiolitis severity score, hMPV: human metapneumovirus, RSV: respiratory syncytial virus.

${ }^{a} \mathrm{r}$ is coefficient correlation.

$* P<0.05$, statistically significant

\section{DISCUSSION}

We identified a viral etiology in $48.6 \%$ of preterm infants and in $67 \%$ of term infants hospitalized with acute bronchiolitis; one or more viral pathogens were detected. RSV was the most frequently isolated respiratory virus in both preterm and term infants with bronchiolitis, and adenovirus was the second most frequently detected virus in the current study. The predominance of RSV is in concordance with the assertion that this virus is the single most frequently identified lower respiratory tract pathogen in hospitalized infants worldwide ${ }^{[17-20]}$. Although RSV significantly affects more term infant in this study, yet it is likely to be associated with more severe disease in preterm infants; this observation is important in planning protocols for bronchiolitis prophylaxis and management in such high-risk preterm infants. Similarly, hMPV and parainfluenza 3 infections were more severe in preterm than term infants. So, physicians treating preterm infants with RSV, hMPV, and parainfluenza 3 bronchiolitis should be aware that their illness is more protracted and runs a more severe course than term infants, even if otherwise healthy. The low prevalence of virus detection among preterm compared with term infants with acute bronchiolitis in this study could be attributed to other respiratory viruses, which were not included in this study, such as coronaviruses, bocaviruses, and rhinoviruses, and may be also, explained by the fact that only patients admitted with severe infections were included in our study.

Although there were no significant differences in the length of stay in PICU and the duration of MV among preterm and term infants, these preterm patients had more frequent need to be managed in PICU, more frequent need for MV, and more prolonged oxygen therapy and hospital stay than term ones. These findings were in accordance with the study by Howidi et al. ${ }^{[21]}$. These differences may be explained by smaller airway and/or suboptimal immune response in preterm infants. In addition, the significant difference in age between the two groups could partly explain the higher severity among preterm group.

We found also significant correlation between bronchiolitis severity scoring and need of hospital admission, the same as for the duration of hospital stay and duration of oxygen therapy. This was similar to results reported by Ricart et al. ${ }^{[22]}$, who found that severe bronchiolitis had more mean length of hospital stays compared with nonsevere and more prolonged duration of oxygen and MV. We documented that preterm infants have a more severe form of illness than term infants, where we found that prematurity significantly affects the severity score of bronchiolitis. Increased illness severity in infants who had bronchiolitis was discussed in several researches ${ }^{[1,23]}$. In this study, we found that preterm infants were significantly younger than those born term, similar to that reported by Fleming et al. ${ }^{[1]}$.

Mixed viral infection and bacterial co-infection in the present study were more frequently observed in preterm compared with term infants with acute bronchiolitis. However, bacterial co-infection was significantly correlated with severity scoring, whereas mixed viral infection did not correlate with severity scoring of bronchiolitis, and this was in consistence with what was reported by others ${ }^{[22,24,25]}$. This indicates that infection with multiple viruses in infants is a common situation that does not change the clinical course of bronchiolitis. However, some studies have 
reported an increased risk for severe bronchiolitis in dual viral infection ${ }^{[26-28]}$ or even in some specific viral infections such as RSV and hMPV co-infection ${ }^{[29-31]}$.

Although respiratory viruses seem to be related to increased risk of severe disease, our data suggest that prematurity has more specific weight in predicting bronchiolitis outcome. So, understanding host susceptibility and immune response of preterm infants to these viruses, as well as targeting the prevention of infection with these viruses in preterm infant may have even broader implications than only focusing on their role in disease morbidity.

\section{LIMITATIONS OF STUDY}

Limiting this study is a possible underestimation of viral etiologies of acute bronchiolitis because testing for rhinoviruses, coronaviruses, and other viruses was not done, and these viruses were previously detected in such patients $^{[32-35]}$. Moreover, the enrolled patients were from a single tertiary institution, which is a referral center for many local hospitals, so enrolled cases may be more ill than those at other hospitals. The enrolled patients were inpatients only, whereas patients with mild respiratory symptoms did not undergo diagnostic testing for viral infections; they were treated in outpatient clinics and this could further direct results toward a more severe population and could influence the scores.

\section{CONCLUSION}

Prematurity is one of the risk factors that significantly affect the bronchiolitis severity, and this underscores the importance of early categorization of these infants as a high-risk group on their first visit. Physicians treating preterm infants with bronchiolitis should be aware that their illness runs a more severe course than term infant, even if they have no underlying disorders.

\section{ACKNOWLEDGEMENTS}

Authors would like to acknowledge all patients included in this study.

\section{CONFLICT OF INTEREST}

There are no coflicts of interest.

\section{REFERENCES}

1. Fleming PF, Richard S, Waterman K, Davis PG, Kamlin $\mathrm{CO}$, Stewart M, et al. Medical retrieval and needs of infants with bronchiolitis: an analysis by gestational age. J Paediatr Child Health 2013; 49:E227-E231.

2. Calvo C, Pozo F, Garcia-Garcia ML, Sanchez M, Lopez-Valero M, Pèrez-Breňa $\mathrm{P}$, et al. Detection of new respiratory viruses in hospitalized infants with bronchiolitis: a three-year prospective study. Acta Pediatr 2010; 99:883-887.

3. Leader S, Kohlhase K. Respiratory syncytial virus coded pediatric hospitalization, 1997 to 1999. Pediatr Infect Dis J 2002; 21:629-632.

4. Bialy L, Foisy M, Smith M, Fernandes RM. The cochrane library and the treatment of bronchiolitis in children: an overview of reviews. Evid Based Child Health 2011; 6:258-275.

5. Che D, Nicolau J, Bergounioux J, Perez T, Bitar D. Bronchiolitis among infants under 1 year of age in France: epidemiology and factors associated with mortality. Arch Pediatr 2012; 19:700-706.

6. Zorc JJ, Hall CB. Bronchiolitis: recent evidence on diagnosis and management. Pediatrics 2010; 125:342-349.

7. Deshpande SA, Northern V. The clinical and health economic burden of respiratory syncytial virus disease among children under 2 years of age in a defined geographical area. Arch Dis Child 2003; 88:1065-1069.

8. Willson DF, Landrigan CP, Horn SD, Smout RJ. Complications in infants hospitalized for bronchiolitis or respiratory syncytial virus pneumonia. J Pediatr 2003; 143:S142-S149.

9. Simoes EA, Carbonell-Estrany X. Impact of severe disease caused by respiratory syncytial virus in children living in developed countries. Pediatr Infect Dis J 2003; 22: S13-S18.

10. Fitzgerald DA. Viral bronchiolitis for children. J Pediatr Child Health 2011; 47:160-166.

11. Bradley JP, Bacharier LB, Bonfiglio J, Schechtman $\mathrm{KB}$, Strunk R, Storch G, et al. Severity of respiratory syncytial virus bronchiolitis is affected by cigarette smoke exposure and atopy. Pediatrics 2005; 115:e7-e14.

12. Sala KA, Moore A, Desai S, Welch K, Bhandari $\mathrm{S}$, Carroll CL. Factors associated with disease severity in children with bronchiolitis. J Asthma 2015; 52:268-272.

13. Chan PW, Lok FY, Khatijah SB. Risk factors for hypoxemia and respiratory failure in respiratory syncytial virus bronchiolitis. Southeast Asian J Trop Med Public Health 2002; 33:806-810.

14. American Academy of Pediatrics Subcommittee 
on Diagnosis and Management of bronchiolitis. Diagnosis and management of bronchiolitis. Pediatrics 2006; 118:1774-1793.

15. McCallum GB, Morris PS, Wilson CC, Versteegh LA, Ward LM, Chatfield MD, et al. Severity scoring systems: are they internally valid, reliable and predictive of oxygen use in children with acute bronchiolitis? Pediatr Pulmonol 2013; 48:797-803.

16. World Health Organization. Information for molecular diagnosis of influenza virus in humans-update. Geneva: WHO; 2010 .

17. Arden KE, McErlean P, Nissen MD, Sloots TP, Mackay IM. Frequent detection of human rhinoviruses, paramyxoviruses, coronaviruses, and bocavirus during acute respiratory tract infections. J Med Virol 2006; 78:1232-1240.

18. Wong S, Pabbaraju K, Pang XL, Lee BE, Fox JD. Detection of a broad range of human adenoviruses in respiratory tract samples using a sensitive multiplex real time PCR assay. J Med Virol 2008; 80:856-865.

19. Rodríguez C, José A, Daszenies C, García M, Meyer $\mathrm{R}$, Gonzales R. Adenovirus pneumonia in infants and factors for developing bronchiolitis obliterans: a 5-year follow-up. Pediatr Pulmonol 2006; 41:947-953.

20. Hall CB, Weinberg GA, Iwane MK, Blumkin AK, Edwards KM, Staat MA, et al. The burden of respiratory syncytial virus infection in young children. N Engl J Med 2009; 360:588-598.

21. Howidi M, Rajah J, Abushrar Z, Parsons H. The severity of respiratory syncytial virus bronchiolitis in young infants in the United Arab Emirates. J Trop Pediatr 2007; 53:22-26.

22. Ricart S, Marcos MA, Sarda M, Anton A, MuñozAlmagro C, Pumarola T. Clinical risk factors are more relevant than respiratory viruses in predicting bronchiolitis severity. Pediatr Pulmonol $2013 ; 48: 456-463$.

23. Zar HJ, Madhi SA, White DA, Masekela R, Risenga $\mathrm{S}$, Lewis $\mathrm{H}$, et al. Acute viral bronchiolitis in South Africa: strategies for management and prevention. S Afr Med J 2016; 106:27-29.

24. Wilkesmann A, Schildgen O, Eis-Hubinger AM, Geikowski T, Glatzel T, Lentze MJ, et al. Human metapneumovirus infections cause similar symptoms and clinical severity as respiratory syncytial virus infections. Eur J Pediatr 2006; 165:467-475.
25. Garcia-Garcia ML, Calvo C, Perez-Brena P, De Cea JM, Acosta B, Casas I. Prevalence and clinical characteristics of human metapneumovirus infections in hospitalized infants in Spain. Pediatr Pulmonol 2006; 41:863-871.

26. Midulla F, Scagnolari C, Bonci E, Pierangeli A, Antonelli G, De Angelis D, et al. Respiratory syncytial virus, human bocavirus and rhinovirus bronchiolitis in infants. Arch Dis Child 2010; 95:35-41.

27. McNamara PS, Flanagan BF, Smyth RL, Hart CA. Impact of human metapneumovirus and respiratory syncytial virus co-infection in severe bronchiolitis. Pediatr Pulmonol 2007; 42:740-743.

28. Richard N, Komurian-Pradel F, Javouhey E, Perret M, Rajoharison A, Bagnaud A, et al. The impact of dual viral infection in infants admitted to a pediatric intensive care unit associated with severe bronchiolitis. Pediatr Infect Dis J 2008; 27:213-217.

29. Semple MG, Cowell A, Dove W, Greensill J, McNamara PS, Halfhide C, et al. Dual infection of infants by human metapneumovirus and human respiratory syncytial virus is strongly associated with severe bronchiolitis. J Infect Dis 2005; 191:382-386.

30. Foulongne V, Guyon G, Rodiere M, Segondy M. Human metapneumovirus infection in young children hospitalized with respiratory tract disease. Pediatr Infect Dis J 2006; 25:354-359.

31. Greensill J, McNamara PS, Dove W, Flanagan B, Smyth RL, Hart CA. Human metapneumovirus in severe respiratory syncytialvirus bronchiolitis. Emerg Infect Dis 2003; 9:372-375.

32. Weiss SR, Navas-Martin S. Coronavirus pathogenesis and the emerging pathogen severe acute respiratory syndrome coronavirus. Microbiol Mol Biol Rev 2005; 69:635-664.

33. Allander $\mathrm{T}$, Jartti $\mathrm{T}$, Gupta $\mathrm{S}$, Niesters $\mathrm{HG}$, Lehtinen $\mathrm{P}$, Üsterback R, et al. Human bocavirus and acute wheezing in children. Clin Infect Dis 2007; 44:904-910.

34. Jacques J, Moret H, Minette D, Leveque N, Jovenin $\mathrm{N}$, Deslée $\mathrm{G}$, et al. Epidemiological, molecular, and clinical features of enterovirus respiratory infections in French children between 1999 and 2005. J Clin Microbiol 2008; 46:206-213.

35. Sloots TP, Whiley DM, Lambert SB, Nissen MD. Emerging respiratory agents: new viruses for old diseases? J Clin Virol 2008; 42:233-243. 